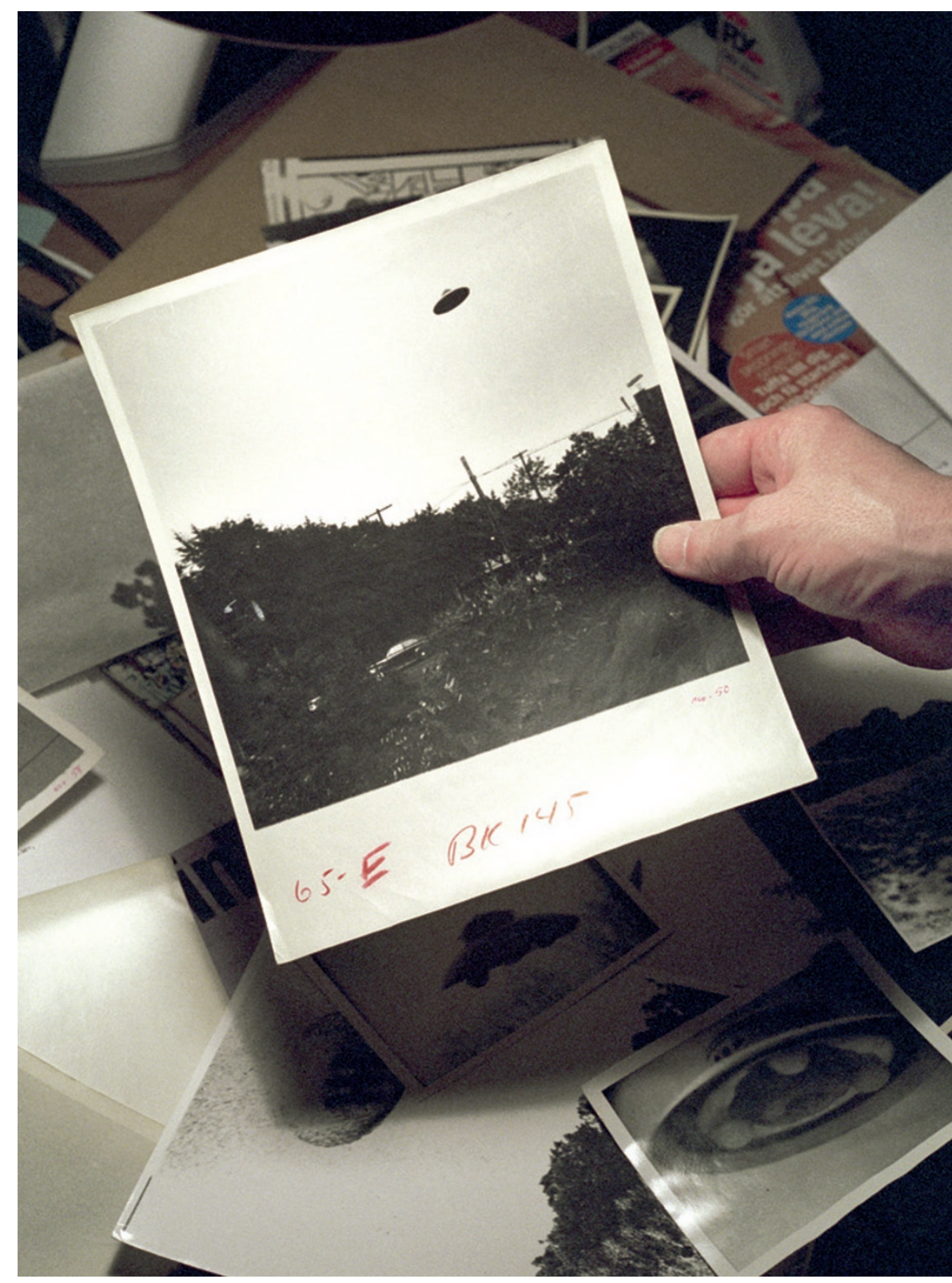

From UFOs to conspiracy theories, we form beliefs and then look for reasons to support them.

\title{
How we form beliefs
}

\section{Religions and superstitions may stem from the brain's ability to spot patterns and intent, finds A. C. Grayling.}

\section{$\mathrm{T}$} wo long-standing observations about human cognitive behaviour provide Michael Shermer with the fundamentals of his account of how people form beliefs. One is the brain's readiness to perceive patterns even in random phenomena. The other is its readiness to nominate agency — intentional action — as the cause of natural events.

Both explain belief-formation in general, not just religious or supernaturalistic belief. Shermer, however, has a particular interest in the latter, and much of his absorbing and comprehensive book addresses the widespread human inclination to believe in gods, ghosts, aliens, conspiracies and the importance of coincidences.

Shermer is well equipped for this task. $\mathrm{He}$ is a psychology professor, the founder of Skeptic magazine and resident sceptical

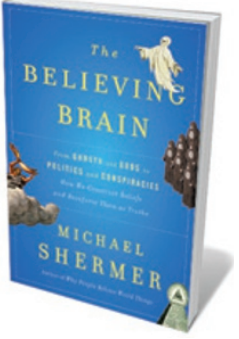

The Believing

Brain: From

Ghosts and Gods to Politics and

Conspiracies -

How We Construct

Beliefs and

Reinforce Them as

Truths

MICHAEL SHERMER

Times Books: 2011.

400 pp. $\$ 28, £ 19.99$ why we form particular beliefs from subjective, personal and emotional promptings, in social and historical environments that influence their content.

As a 'belief engine', the brain is always seeking to find meaning in the information that pours into it. Once it has constructed a belief, it rationalizes it with explanations, almost always after the event. The brain thus becomes invested in the beliefs, and reinforces them by looking for supporting evidence while blinding itself to anything contrary. Shermer describes this process as "belief-dependent realism" - what we believe determines our reality, not the other way around.

He offers an evolution-based analysis of why people are prone to forming supernatural beliefs based on patternicity and agenticity. Our ancestors did well to wonder whether rustling in the grass indicated a predator, even if it was just the breeze. Spotting a significant pattern in the data may have meant an intentional agent was about to pounce.

Problems arise when thinking like this is unconstrained, he says. Passionate investment in beliefs can lead to intolerance and conflict, as history tragically attests. Shermer gives chilling examples of how dangerous belief can be when it is maintained against all evidence; this is especially true in pseudoscience, exemplified by the death of a ten-year-old girl who suffocated during the cruel 'attachment therapy' once briefly popular in the United States in the late 1990s.

Shermer's account implies that we are far from being rational and deliberative think- $\rightarrow$ NATURE.COM Pascal Boyer on religion and neuroscience: go.nature.com/gpilibe ers, as the Enlightenment painted us. Patternicity leads us to see significance in mere 'noise' as well as in meaningful data; 
agenticity makes us ascribe purpose to the source of those meanings. How did we ever arrive at more objective and organized knowledge of the world? How do we tell the difference between noise and data?

His answer is science. "Despite the subjectivity of our psychologies, relatively objective knowledge is available," Shermer writes. This is right, although common sense and experience surely did much to make our ancestors conform to the objective facts long before experimental science came into being; they would not have survived otherwise.

Powerful support for Shermer's analysis emerges from accounts he gives of highly respected scientists who hold religious beliefs, such as US geneticist Francis Collins. Although religious scientists are few, they are an interesting phenomenon, exhibiting the impermeability of the internal barrier that allows simultaneous commitments to science and faith. This remark will be regarded as outrageous by believing scientists, who think that they are as rational in their temples as in their laboratories, but scarcely any of them would accept the challenge to mount a controlled experiment to test the major claims of their faith, such as asking the deity to regrow a severed limb for an accident victim.

Shermer deals with the idea that theistic belief is an evolved, hard-wired phenomenon, an idea that is fashionable at present. The existence of atheists is partial evidence against it. More so is that the god-believing religions are very young in historical terms; they seem to have developed after and perhaps because of agriculture and associated settled urban life, and are therefore less than 10,000 years old.

The animism that preceded these religions, and which survives today in some traditional societies such as those of New Guinea and the Kalahari Desert, is fully explained by Shermer's agenticity concept. It is not religion but proto-science - an attempt to explain natural phenomena by analogy with the one causative power our ancestors knew well: their own agency. Instead of developing into science, this doubtless degenerated into superstition in the hands of emerging priestly castes or for other reasons, but it does not suggest a 'god gene' of the kind supposed for history's young religions with their monarchical deities.

This stimulating book summarizes what is likely to prove the right view of how our brains secrete religious and superstitious belief. Knowledge is power: the corrective of the scientific method, one hopes, can rescue us from ourselves in this respect.

A. C. Grayling is professor of philosophy at Birkbeck College, University of London. His latest publication is The Good Book. e-mail:a.grayling@philosophy.bbk.ac.uk

\section{Books in brief}

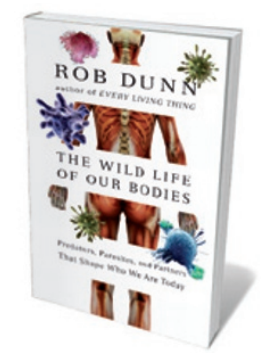

The Wild Life of Our Bodies: Predators, Parasites, and Partners That Shape Who We Are Today

Rob Dunn HARPER 304 pp. \$26.99 (2011)

Ridding our bodies of microbes is one of the goals of modern medical science and sanitation. But antibiotics and cleanliness might be causing us more harm than good, according to biologist Rob Dunn. In his provocative book, he sings the praises of intestinal worms for keeping our guts healthy, and urges us to 'rewild' our internal ecosystems. By distancing ourselves from other wildlife, he argues, humans are harming themselves both mentally and physically. The cure is to get our bodies back in touch with other species.

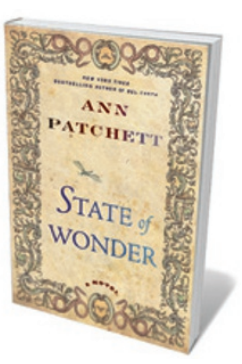

\section{State of Wonder: A Novel}

Ann Patchett HARPER 368 pp. $\$ 26.99$ (2011)

A research scientist is the heroine of best-selling author Ann Patchett's latest novel. Marina Singh is called away from her lab bench at a large pharmaceutical company in Minnesota to search in the Brazilian rainforest for her old mentor, who has disappeared while looking for medicinal plants. The last person sent out to Brazil on the same mission was Singh's research partner and friend, who never returned. Singh tracks down her mentor, but what she finds in the jungle raises questions about her friend's fate, her company's future and her own past.

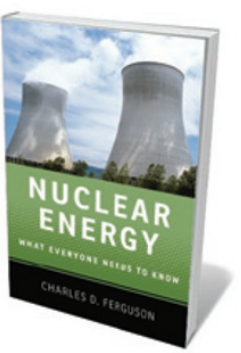

Nuclear Energy: What Everyone Needs to Know

Charles D. Ferguson OXFORD UNIVERSITY PRESS 240 pp. \$16.95 (2011) With concerns about nuclear energy on the rise after Japan's Fukushima disaster, security scholar Charles Ferguson's accessible overview is timely. He sets out how nuclear power is generated, which countries use it and how much electricity they produce. He discusses safety issues, from defending plants against military attacks to technical failures. And he notes the roller-coaster of public attitudes to nuclear power, which have oscillated in the past decade from growing acceptance of its utility in reducing greenhouse-gas emissions to recent proposals to abandon the industry.

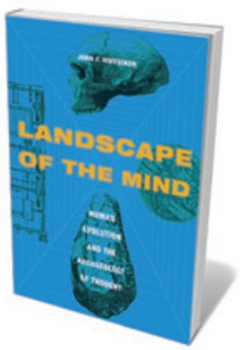

Landscape of the Mind: Human Evolution and the Archaeology of Thought

John F. Hoffecker COLUMBIA UNIVERSITY PRESS 288 pp. \$50 (2011)

The origins of the human mind may lie in feedbacks between our brains, hands and tools, suggests palaeoanthropologist John Hoffecker. Social, physical and mental experiences combined long ago to form a 'superbrain' network, he suggests, giving rise to consciousness and creativity. Technologies were integral to expanding our horizons and to abstract thinking. Archaeological evidence links the rise of symbolism with tool development, following people's adaptation to different climates as they spread worldwide.

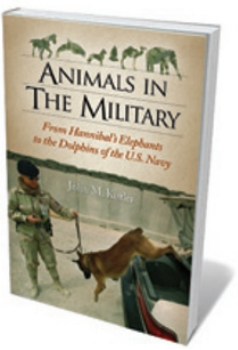

Animals in the Military: From Hannibal's Elephants to the Dolphins of the U.S. Navy

John M. Kistler ABC CLIO 343 pp. £44.95 (2011)

Animals have a long history in the military, as writer John Kistler recounts. Horses have lugged men and equipment across the battlefields of history and are still in use today in combating Taliban fighters in remote regions of Afghanistan. Elephants, dogs and stinging insects have been used to attack enemies. Kistler relates the heroics and horrors of animals in warfare, from the dolphins of the US Navy to message-delivering pigeons and mine-sniffing rats. 